\title{
Treatment and survival analyses of completely resected thymic carcinoma patients
}

\author{
This article was published in the following Dove Press journal: \\ OncoTargets and Therapy \\ 9 September 2015 \\ Number of times this article has been viewed
}

\section{Yanjiao Mao \\ Shixiu Wu}

Department of Radiotherapy Oncology, Hangzhou Cancer Hospital, Hangzhou, People's Republic of China
Correspondence: Shixiu Wu Department of Radiotherapy Oncology, Hangzhou Cancer Hospital, Hangzhou 310022, People's Republic of China Tel +8657I 65882999 Fax +86 57। 65882996 Email wushixiuhangzhou@I63.com
Purpose: To investigate the impact of chemotherapy and/or radiotherapy on disease-free survival (DFS) and overall survival (OS) rates of patients with thymic carcinoma after complete resection. Methods: Between 2001 and 2013, 54 patients with complete resection of thymic carcinoma in Hangzhou Cancer Hospital were retrospectively reviewed. The Kaplan-Meier method was used to evaluate the survival rates. The Cox proportional hazard model was used for multivariate analysis. Results: Among the 54 patients, Masaoka stage I was observed in seven patients, II in 22 patients, and III in 25 patients. Sixteen patients received adjuvant chemotherapy (six with chemotherapy alone and ten with radiotherapy and chemotherapy), 25 patients received adjuvant radiotherapy, and 13 patients did not receive radiotherapy and/or chemotherapy. The 5-year DFS and OS rates for all patients were $63.0 \%$ and $73.4 \%$, respectively. Univariate analysis revealed that radiotherapy was significantly associated with DFS and OS ( $P=0.014$ and $P=0.029$, respectively), while adjuvant chemotherapy was not $(P=0.122$ and $P=0.373$, respectively). Multivariate analysis showed that adjuvant radiotherapy increased DFS $(P=0.041)$, but not OS $(P=0.051)$.

Conclusion: Complete resection followed by adjuvant radiotherapy increased disease-free rates of thymic carcinoma patients.

Keywords: thymic carcinoma, complete resection, adjuvant treatment, radiotherapy, chemotherapy, overall survival

\section{Introduction}

Thymic carcinoma is a relatively rare mediastinal tumor. ${ }^{1}$ Surgery is the standard treatment for early-stage thymic carcinoma, and complete resection is the most important prognostic factor for survival. ${ }^{2,3}$ Although chemotherapy and radiation are widely applied in thymic carcinoma, the role of adjuvant chemotherapy and/or radiotherapy after complete resection remains controversial with very few studies. ${ }^{4-6}$

According to the guidelines of the National Comprehensive Cancer Network, systemic chemotherapy was not recommended after complete resection of thymic carcinoma, but radiotherapy was recommended after complete tumor resection in stages II and III of thymic carcinoma; however, the recommended category is low. Studies focusing on adjuvant treatment after resection of thymic carcinoma are lacking now. ${ }^{5}$

In this study, we retrospectively evaluated the prognosis and treatment of patients with completely resected thymic carcinoma and explored the impact of chemotherapy and/or radiotherapy on disease-free survival (DFS) and overall survival (OS) rates of patients with thymic carcinoma after complete resection.

\section{Patients and methods Methods}

Fifty-four patients who had complete resection for thymic carcinoma between January 2001 and December 2013 in Hangzhou Cancer Hospital were included in the study. 
Based on the Masaoka staging system, the stage of thymic carcinoma was classified. Pathologically proven primary type C (WHO histological classification) thymic carcinoma by surgery. All patients underwent complete resection, and pathology proved no positive margins. No patients underwent induction chemotherapy or radiotherapy before surgery. Recurrence or metastases were confirmed using chest computed tomography (CT) as well as ultrasound and/or CT of the abdomen. The study was approved by the Ethics Committee of Hangzhou Cancer Hospital (Hangzhou, People's Republic of China). All patients provided written informed consent for this study.

\section{Follow-up}

Surviving patients were followed every 3-6 months for the first 5 years and then annually. The history, physical examination, and chest CT scan were recorded during the follow-up time. Survival case was recorded from the first day of operation to the date of death or last follow-up time. December 2014 was the last censoring date for survival. The median time from surgery to the last censoring date was 72 months, ranging from 25 to 168 months.

\section{Statistical analysis}

The survival curves were generated using the Kaplan-Meier method and compared with log-rank test. The Cox proportional hazard model was applied for multivariate analysis. The statistical analysis using the SPSS Version 16 (SPSS Inc., Chicago, IL, USA) was performed.

\section{Results}

\section{Patient characteristics}

Patient characteristics and histological subtypes are listed in Table 1. The median age was 49 years (range, 22-74 years). Squamous cell carcinoma (70.4\%) was the most common histological subtype followed by undifferentiated carcinoma and neuroendocrine tumors. Among the 54 patients, five patients had positive mediastinal lymph nodes at surgical resection. Performance score was 0 in 39 patients and 1 for $27.8 \%$ patients. Two young males (aged 31 years and 33 years) presented with myasthenia gravis at first diagnosis with elevated AChR-binding antibody levels. The pathology report confirmed no component of thymoma in these two cases.

\section{Treatment after operation}

All 54 patients underwent complete surgical resection. Sixteen patients underwent chemotherapy (six with only chemotherapy and ten with radiotherapy and chemotherapy),
Table I Demographic characteristics of the study population

\begin{tabular}{ll}
\hline Characteristics & Number (\%) \\
\hline Sex & \\
Male & $26(48.1)$ \\
Female & $28(51.9)$ \\
Age & \\
Range & $22-74$ \\
Median & 49 \\
$<50$ & $29(53.7)$ \\
$\geq 50$ & $25(46.3)$ \\
PS & \\
0 & $39(72.2)$ \\
I & $15(27.8)$ \\
Myasthenia gravis & \\
Yes & $2(3.8)$ \\
No & $52(96.2)$ \\
Masaoka stage & \\
I & $7(13.0)$ \\
II & $22(40.7)$ \\
III & $25(46.3)$ \\
Squamous cell carcinoma & \\
Undifferentiated carcinoma & $38(70.4)$ \\
Neuroendocrine tumor & $9(16.7)$ \\
Others & $4(7.4)$ \\
Treatment after resection & $3(5.5)$ \\
Radiotherapy & \\
Radiotherapy + chemotherapy & $25(46.3)$ \\
No & $16(29.6)$ \\
Abotherapy & $10(18.5)$ \\
\hline & $13(24.6)$ \\
\hline
\end{tabular}

Abbreviation: PS, performance score.

25 patients received radiotherapy, and 13 patients did not receive radiotherapy and/or chemotherapy (Table 1). On day 1 , the most common regimen was the combination of cyclophosphamide $\left(400 \mathrm{mg} / \mathrm{m}^{2}\right)$, adriamycin $\left(40 \mathrm{mg} / \mathrm{m}^{2}\right)$, and cisplatin $\left(75 \mathrm{mg} / \mathrm{m}^{2}\right)(\mathrm{n}=8)$; the second common regimen was the combination of taxol $\left(175 \mathrm{mg} / \mathrm{m}^{2}\right)$ and cisplatin $\left(75 \mathrm{mg} / \mathrm{m}^{2}\right)$ $(\mathrm{n}=6)$; and other regimens included docetaxel $\left(75 \mathrm{mg} / \mathrm{m}^{2}\right)$ and cisplatin $\left(75 \mathrm{mg} / \mathrm{m}^{2}\right)(\mathrm{n}=1)$ as well as vinorelbine $\left(25 \mathrm{mg} / \mathrm{m}^{2}\right)$ and cisplatin $\left(75 \mathrm{mg} / \mathrm{m}^{2}\right)(\mathrm{n}=1)$. Two-dimensional radiotherapy planning system was used in eleven patients and three-dimensional conformal radiotherapy in 14 patients. The median dose was 54.2 Gy (range, 52-61.2 Gy). There were no differences among age $(P=0.47)$, sex $(P=0.52)$, Masaoka stage $(P=0.76)$, and histology $(P=0.31)$ between the radiotherapy and no-radiotherapy patients.

\section{Factors affecting OS by univariate and multivariate analyses}

The 5-year DFS and OS rates for all patients were $63.0 \%$ and $73.4 \%$, respectively. The results of univariate analysis for DFS and OS are listed in Table 2. Age, sex, chemotherapy, 
Table 2 Univariate analysis of the patient survival according to the clinicopathologic characteristics

\begin{tabular}{|c|c|c|c|c|}
\hline Characteristics & $\begin{array}{l}5 \text {-year DFS } \\
\text { rate }(\%)\end{array}$ & $P$-value & $\begin{array}{l}5 \text {-year OS } \\
\text { rate }(\%)\end{array}$ & $P$-value \\
\hline Sex & & 0.091 & & 0.157 \\
\hline Male & 56.5 & & 70.6 & \\
\hline Female & 80.6 & & 81.5 & \\
\hline Age & & 0.129 & & 0.214 \\
\hline$<50$ & 78.5 & & 77.1 & \\
\hline$\geq 50$ & 60.4 & & 67.2 & \\
\hline Histology & & 0.097 & & 0.412 \\
\hline Squamous cell carcinoma & 69.5 & & 77.6 & \\
\hline Others & 60.1 & & 65.7 & \\
\hline PS & & 0.605 & & 0.614 \\
\hline 0 & 79.5 & & 68.5 & \\
\hline I & 59.2 & & 82.3 & \\
\hline Myasthenia gravis & & 0.514 & & 0.512 \\
\hline Yes & 66.5 & & 81.5 & \\
\hline No & 61.1 & & 64.5 & \\
\hline Adjuvant chemotherapy & & 0.122 & & 0.373 \\
\hline Yes & 56.2 & & 72.9 & \\
\hline No & 66.7 & & 73.8 & \\
\hline Adjuvant radiotherapy & & 0.014 & & 0.029 \\
\hline Yes & 77.5 & & 78.6 & \\
\hline No & 44.1 & & 66.4 & \\
\hline Masaoka stage & & 0.102 & & 0.129 \\
\hline I & 85.7 & & 85.7 & \\
\hline II & 66.0 & & 77.5 & \\
\hline III & 53.1 & & 58.3 & \\
\hline
\end{tabular}

Abbreviations: DFS, disease-free survival; OS, overall survival; PS, performance score.

histology, myasthenia gravis, and Masaoka stage showed no significant association with DFS and OS (Table 2), while radiotherapy showed significant association with DFS and OS ( $P=0.014$ and $P=0.029$, respectively) (Figures 1 and 2 ). There were significant differences for DFS among the radiotherapy alone, radiotherapy and chemotherapy, chemotherapy alone,

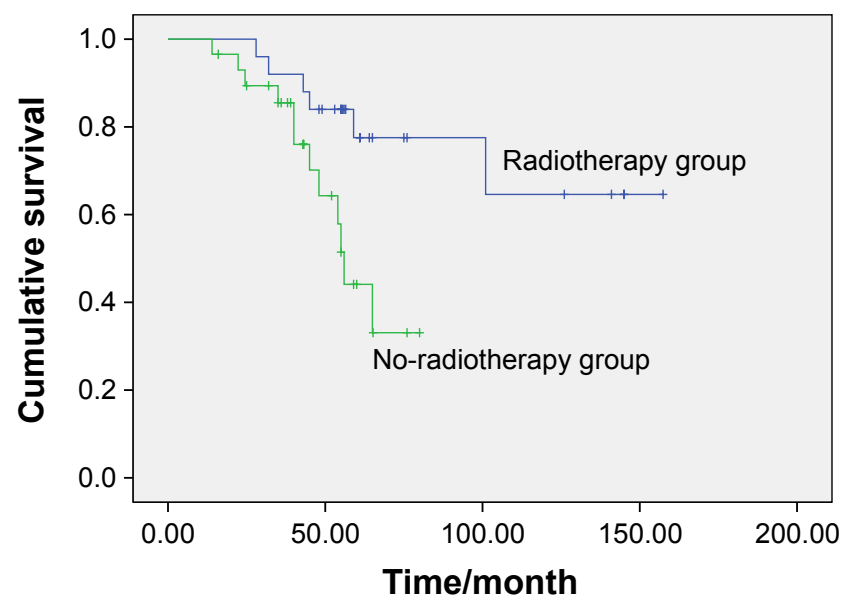

Figure I DFS in radiotherapy group and no-radiotherapy treatment group $(P=0.014)$. Abbreviation: DFS, disease-free survival.

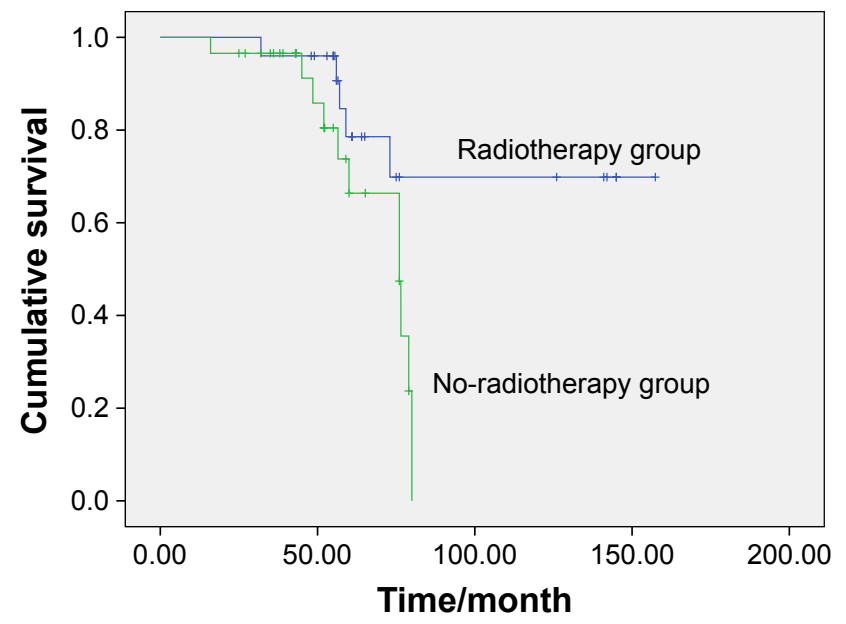

Figure 2 OS in radiotherapy group and no-radiotherapy treatment group $(P=0.029)$. Abbreviation: OS, overall survival.

and no adjuvant treatment patients $(P=0.013)$, but not for OS $(P=0.054)$ (Figures 3 and 4$)$.

A multivariate Cox regression model showed that adjuvant radiotherapy and stage significantly influenced DFS, but not OS (Table 3).

\section{Discussion}

Due to the rarity of thymic tumors, randomized controlled data are lacking, and the available evidence on adjuvant treatment comes from small retrospective studies. Our results suggest that adjuvant radiotherapy after complete resection could impact the DFS rates of thymic carcinoma patients.

The role of postoperative radiation therapy and chemotherapy in reducing the rate of recurrence and increasing the OS remains controversial. A multi-institutional retrospective study ${ }^{7}$ demonstrated that adjuvant radiation does not improve the OS rate in patients with completely resected thymic

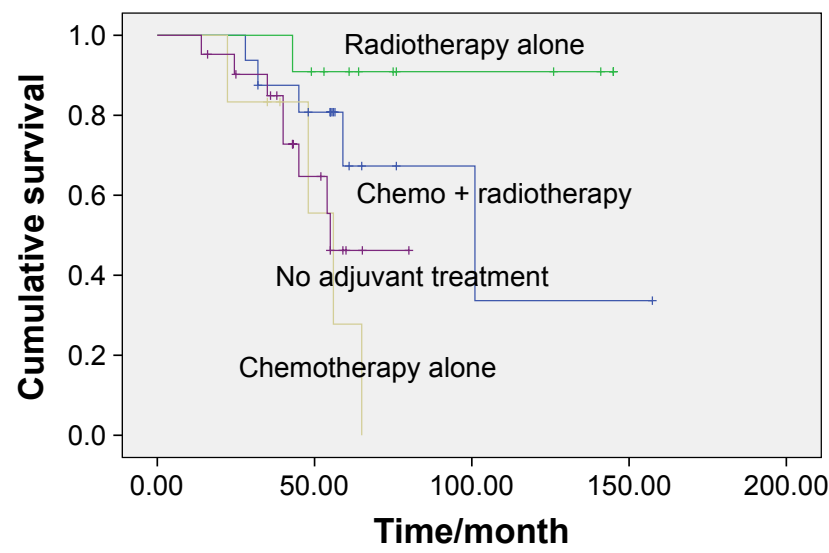

Figure 3 DFS among the radiotherapy alone, radiotherapy and chemotherapy, chemotherapy alone, and no adjuvant treatment group $(P=0.013)$. Abbreviation: DFS, disease-free survival. 


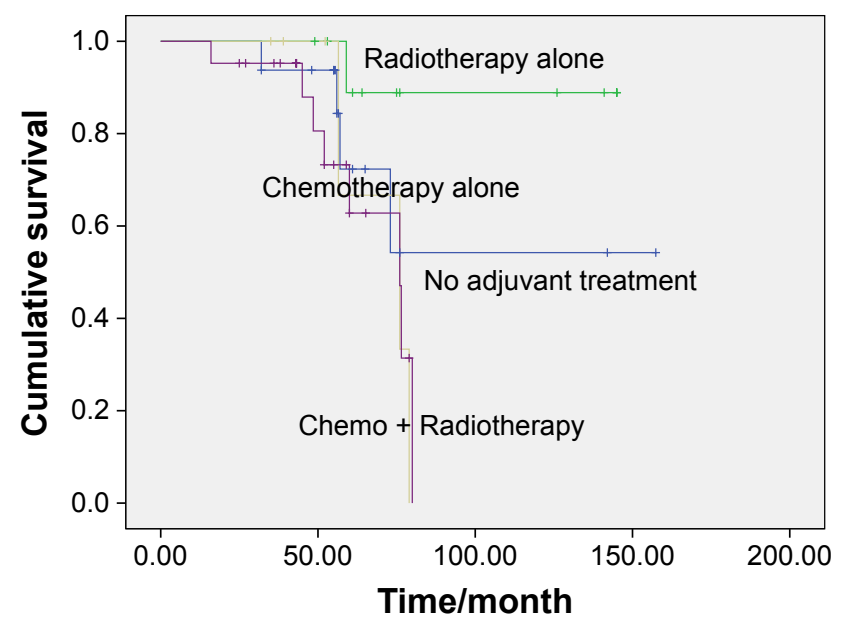

Figure 4 OS among the radiotherapy alone, radiotherapy and chemotherapy, chemotherapy alone, and no adjuvant treatment group $(P=0.054)$. Abbreviation: OS, overall survival.

carcinoma. In contrast, another multi-institutional retrospective study by Omasa et al showed that postoperative radiotherapy increased relapse-free survival for stages II and III thymic carcinoma. ${ }^{8}$ Patel et al reported the results of 1,464 patients with thymic carcinoma from centers that participated in the Surveillance, Epidemiology, and End Results program, ${ }^{9}$ which indicated that OS significantly improved with radiotherapy, and an improved cause-specific survival trend was observed. In this study, the patients benefited from adjuvant radiotherapy, which is consistent with the findings of Omasa et al.

Adjuvant chemotherapy in some studies showed a benefit of reducing distant metastasis rate and prolonging OS and others did not indicate any role. ${ }^{5,10-16}$ Song and Zhang ${ }^{5}$ and Sun et $\mathrm{al}^{16}$ found no DFS and OS differences in completely resected thymic carcinoma patients receiving surgery alone versus surgery plus adjuvant chemotherapy. Our series also revealed that adjuvant chemotherapy showed no significant effect in completely resected thymic carcinoma.

Table 3 Multivariate survival analysis for DFS and OS

\begin{tabular}{|c|c|c|c|c|c|c|}
\hline \multirow[t]{2}{*}{ Parameters } & \multicolumn{3}{|c|}{ DFS } & \multicolumn{3}{|l|}{ OS } \\
\hline & HR & $95 \% \mathrm{Cl}$ & $P$-value & HR & $95 \% \mathrm{Cl}$ & $P$-value \\
\hline Sex (male vs female) & 2.15 & $0.43-3.21$ & 0.76 & 4.2 & $0.35-4.87$ & 0.51 \\
\hline $\begin{array}{l}\text { Adjuvant chemotherapy } \\
\text { (yes vs no) }\end{array}$ & 1.57 & $0.21-5.21$ & 0.55 & 1.21 & $0.11-1.97$ & 0.54 \\
\hline $\begin{array}{l}\text { Adjuvant radiotherapy } \\
\text { (yes vs no) }\end{array}$ & 0.67 & $0.42-0.95$ & $0.04 I$ & 0.67 & $0.43-101$ & 0.051 \\
\hline Stage (I + II vs III) & 0.47 & $0.43-0.99$ & 0.042 & 0.54 & $0.33-1.88$ & 0.056 \\
\hline $\begin{array}{l}\text { Histologic subtype } \\
\text { (squamous cell vs } \\
\text { other types) }\end{array}$ & 0.45 & $0.32-5.54$ & 0.24 & 0.76 & $0.43-3.98$ & 0.21 \\
\hline
\end{tabular}

Abbreviations: DFS, disease-free survival; OS, overall survival; HR, hazard ratio; $\mathrm{Cl}$, confidence interval.
Our study is limited by its retrospective nature and with a small number of patients included. However, considering the rarity of the disease, the report of 54 cases is regarded as a relatively large study; our retrospective study may also be meaningful.

\section{Conclusion}

In summary, adjuvant radiotherapy after complete resection of thymic carcinoma could increase DFS. Prospective trials are required to further elucidate the effect and survival after adjuvant chemotherapy and radiation.

\section{Disclosure}

The authors report no conflicts of interest in this work.

\section{References}

1. Engels EA. Epidemiology of thymoma and associated malignancies. J Thorac Oncol. 2010;5(1):S260-S265.

2. Song Z, Zhang Y. Outcomes after surgical resection of thymic carcinoma: a study from a single tertiary referral centre. Eur J Surg Oncol. 2014; 40(11):1523-1527.

3. Venuta F, Anile M, Diso D, et al. Thymoma and thymic carcinoma. Eur J Cardiothorac Surg. 2010;37(1):13-25.

4. Shen S, Ai X, Lu S. Long-term survival in thymic epithelial tumors: a single-center experience from China. $J$ Surg Oncol. 2013;107(2): $167-172$.

5. Song Z, Zhang Y. Adjuvant therapy in stage II thymic carcinoma. J Cancer Res Clin Oncol. 2014;140(2):349-352.

6. Fan C, Feng Q, Chen Y, et al. Postoperative radiotherapy for completely resected Masaoka stage III thymoma: a retrospective study of 65 cases from a single institution. Radiat Oncol. 2013;13:199.

7. Kondo K, Monden Y. Therapy for thymic epithelial tumors: a clinical study of 1,320 patients from Japan. Ann Thorac Surg. 2003;76(3): 878-884.

8. Omasa M, Date H, Sozu T, et al; Japanese Association for Research on the Thymus. Postoperative radiotherapy is effective for thymic carcinoma but not for thymoma in stage II and III thymic epithelial tumors: the Japanese Association for Research on the Thymus Database Study. Cancer. 2015;121(7):1008-1016.

9. Patel S, Macdonald OK, Nagda S, Bittner N, Suntharalingam M. Evaluation of the role of radiation therapy in the management of malignant thymoma. Int J Radiat Oncol Biol Phys. 2012;82(5):1797-1801.

10. Sakai M, Onuki T, Inagaki M, et al. Early-stage thymic carcinoma: is adjuvant therapy required? J Thorac Dis. 2013;5(2):161-164.

11. Kondo K, Monden Y. Lymphogenous and hematogenous metastasis of thymic epithelial tumors. Ann Thorac Surg. 2003;76(6):1859-1864.

12. Lee CY, Bae MK, Park IK, Kim DJ, Lee JG, Chung KY. Early Masaoka stage and complete resection is important for prognosis of thymic carcinoma: a 20-year experience at a single institution. Eur J Cardiothorac Surg. 2009;36(1):159-162.

13. Weksler B, Dhupar R, Parikh V, Nason KS, Pennathur A, Ferson PF. Thymic carcinoma: a multivariate analysis of factors predictive of survival in 290 patients. Ann Thorac Surg. 2013;95(1):299-303.

14. Filosso PL, Guerrera F, Rendina AE, et al. Outcome of surgically resected thymic carcinoma: a multicenter experience. Lung Cancer. 2014;83(2): 205-210.

15. Okereke IC, Kesler KA, Freeman RK, et al. Thymic carcinoma: outcomes after surgical resection. Ann Thorac Surg. 2012;93(5):1668-1672.

16. Sun Y, Liu J, Yu X. Treatment and prognosis of Masaoka stage 3 thymic carcinoma: a retrospective study of 32 cases. Onco Targets Ther. 2015;8: 699-702. 
OncoTargets and Therapy

\section{Publish your work in this journal}

OncoTargets and Therapy is an international, peer-reviewed, open access journal focusing on the pathological basis of all cancers, potential targets for therapy and treatment protocols employed to improve the management of cancer patients. The journal also focuses on the impact of management programs and new therapeutic agents and protocols on

patient perspectives such as quality of life, adherence and satisfaction The manuscript management system is completely online and includes a very quick and fair peer-review system, which is all easy to use. Visit http://www.dovepress.com/testimonials.php to read real quotes from published authors.

Submit your manuscript here: http://www.dovepress.com/oncotargets-and-therapy-journal 